\title{
TEORIA E PRÁXIS NO “CHÃO DA ESCOLA”
}

\author{
Alexandra Cavalcante Pessoa ${ }^{1}$ \\ Maria Cristina de Távora Sparano
}

\section{Resumo:}

Este artigo objetiva realizar uma reflexão crítica sobre a educação escolarizada, examinando as ações pedagógicas próprias de educadores e educandos, à luz da Teoria Comunicacional do filósofo e sociólogo alemão Jurgen Habermas, tendo como fonte discursiva um projeto institucional da Secretaria de Estado da Educação do Governo do Piauí, denominado "Formação no chão da escola". Considerando a importância da abertura à experiência comunicativa na educação e na sociedade, exacerbadamente funcionalistas, o estudo da inter-relação teoria e práxis, notoriamente sistematizada e problemática, conduz-nos ao resgate dos conceitos-chave da filosofia crítica habermasiana: "mundo da vida e mundo sistêmico", para, a partir deles e através deles, compreender e confrontar essa realidade pedagógica nefasta, produto de uma escola administrada enquanto subsistema do mundo vital, criticando substancialmente esse processo de formação educativo tão midiático e colonizado por todas as formas de habilidades regidas pela racionalidade instrumental. Concluímos com a proposta de Habermas de uma práxis pedagógica emancipatória, perfeitamente possível e carente de discussão, coordenação e entendimento, via linguagem intersubjetiva.

Palavras-chave: Educação; Racionalidade; Teoria comunicacional; Emancipação.

\section{THEORY AND PRAXIS ON THE "SCHOOL FLOOR"}

\begin{abstract}
:
This article aims at a critical reflection on school education, examining the pedagogical actions proper to educators and students in the light of the Communication Theory of the German philosopher and sociologist Jurgen Habermas and taking as a discursive source an institutional project of the State Secretariat of Education of the Piauí Government, called "Formação no chão da escola"(Formation on the school floor). Considering the importance of openness to the communicative experience in education and in a society that is exaggeratedly functionalist, the study of the interrelationship between theory and practice, notoriously systematized and problematic, leads us to the rescue of the key concepts of habermasian critical philosophy: the world of life and the systemic world, in order, from and through them, to understand and confront this harmful pedagogical reality, the product of a school administered as a subsystem of the vital world, substantially criticizing this process of educational formation that is so mediated and colonized by all forms of abilities governed by instrumental rationality. We conclude with Habermas' proposal of an emancipatory pedagogical practice, perfectly possible and lacking in discussion, coordination and understanding via intersubjective language.
\end{abstract}

Keywords: Education; Rationality; Communication Theory; Emancipation.

\section{Introdução}

A transformação de atitudes e comportamentos referentes a aspectos arraigados em nossa cultura, causadores de persistentes injustiças em nossa sociedade, é um dos maiores desafios em qualquer processo de educação social. O contexto atual da educação debate sobre uma escola preparada para proporcionar um ensino esclarecedor e emancipador, respeitando a

\footnotetext{
${ }^{1}$ Mestra em Filosofia - PROF-FILO UFPI. Especialista em Ética e Filosofia Política - UFPI. Graduada em Filosofia - UFPI. cavalcante.pessoa@ bol.com.br

${ }^{2}$ Professora Doutora de Filosofia da UFPI e Coordenadora do Mestrado em Filosofia - PROF - FILO. Psicanalista e membro do GT Filosofia e Psicanálise da Anpof. cris-sparano@ufpi.edu.br
} 
heterogeneidade e a individualidade da comunidade escolar; ensino bem diferente do que temos. Assim, o alinhamento entre teoria e prática proporcionará sempre um caminho mais seguro diante do cenário desafiador em que as instituições educacionais se encontram.

Todavia, nem sempre tal alinhamento é amistoso, fértil e de fácil visibilidade; pelo contrário, a dissociação entre ambas é muito mais notória. De maneira geral, ações ditas educativas devem ser executadas a partir de uma teoria e/ou tendência científica, pedagógica, filosófica, mas na prática, nem sempre isso acontece. O que se percebe de forma nítida é, de um lado, um ativismo prejudicial (confundindo-se, às vezes, com militância); de outro, um obsoleto modo de verbalizar descontextualizado e preguiçoso, ressonância de um funcionalismo público decadente e carente de estudo e pesquisa. Agem como se as competências pudessem existir sem os conhecimentos construídos historicamente, como se a partir de seus próprios construtos emocionais algo pudesse ser introjetado no meio escolar, abrindo as portas da cidadania e justiça social, no sentido mais clássico que tais termos possam carregar.

Vê-se, pois, que "de modo semelhante ao que ocorreu no trabalho fabril, pretendese a objetivação do trabalho pedagógico. O concurso das ações de diferentes sujeitos produz assim um resultado com o qual nenhum dos sujeitos se identifica e que, ao contrário, lhes é estranho" (Saviani, 2009, p. 23-24). O fenômeno acima mencionado - típico do período conhecido como Revolução Industrial, iniciado no século XVIII - permite-nos uma leitura crítica da "organização racional" à qual nos sujeitamos atualmente. O nervo da ação educativa na relação interpessoal passa a ser o condicionamento racional dos meios, relegando os sujeitos do processo educativo (professor-aluno) à condição de executores de um processo cuja concepção, planejamento, coordenação e controle ficam a cargo de especialistas-técnicos, supostamente capazes de garantir a eficiência e o equilíbrio do sistema (o enfoque é sistêmico).

Indivíduos são educados/treinados para a execução das múltiplas tarefas demandadas continuamente pelo sistema social, preenchendo um modelo de planificação bem funcionalista, o que apresenta sinais visíveis de exaustão, pois o homem sente, pensa e tem vontades, e a partir do momento em que é cerceado nesses aspectos, torna-se estéril intelectualmente, uma massa amorfa de manobras estratégicas, embora muitas vezes tal anomalia seja até insensível. O fato é que o sistema educativo não nos prepara para esse tipo de equalização emocional, não nos conduz a uma reflexão crítica desse mundo e das mais variadas necessidades humanas que emanam nele e por ele. Pelo contrário, a escola deixa de ser um

\begin{tabular}{|c|c|c|c|c|}
\hline Rovista Dialectus & Ano 9 & n. 20 & Outubro - Novembro 2020 & p. $10-26$ \\
\hline
\end{tabular}


contexto de construção comunicativa dos conhecimentos e dos valores próprios da vivência dos alunos e dos professores, limitando-se a um perfil informacional.

A propósito, foi a partir desse perfil, incorporado em ações veiculadas na rotina escolar, que observamos a necessidade de uma pesquisa a respeito daquilo que se entende institucionalmente como formação pedagógica, capaz de conduzir os indivíduos envolvidos a uma "postura diferente" no âmbito socioeducativo. Em 2016, acompanhando a formação do projeto "Chão da escola" 3 ", cujo objetivo é capacitar profissionais da educação de todo o Estado do Piauí, para lidar, da melhor forma, com o planejamento pedagógico, avaliações interdisciplinares, currículo interdisciplinar e situações específicas no cenário da educação, observamos, criticamente, o quanto essa capacitação, embora com propósito interessante, é fragmentada, não respondendo aos problemas identificados pela comunidade escolar, não promovendo a valorização da prática docente, entre outras necessidades básicas da escola, que há muito tempo discute-se nos encontros ou reuniões dirigidas a tais fins.

Muito embora a equipe escolar seja capaz de seguir os planejamentos baseados nas diretrizes da secretaria de educação, montar processos avaliativos que sintetizem o desempenho dos alunos, inserir tecnologias em sua didática, ajuntar a comunidade em torno de uma ação estratégica de cunho formativo; torna-se estática quanto a uma análise teórico-crítica dos métodos de ensino e dos sujeitos que fazem parte do processo de ensino-aprendizagem, tampouco consegue ir além da operacionalização das tecnologias, reduzindo sua importância a uma funcionalidade ardil, o que compromete sobremaneira a relação fértil entre teoria e práxis. “A relação entre os dois pólos: do conhecimento e da ação não pode ser dissociada." (Veiga, 2011, p. 83).

Diferentemente desse modelo de racionalidade, a educação, segundo a ótica da racionalidade comunicativa, possibilita que se levem em conta, além dos elementos cognitivos e instrumentais da razão, os elementos éticos, estéticos e expressivos, minimizados pelo sistema funcional. Assim sendo, no telos da linguagem pragmática, Habermas encontra elementos para restabelecer o poder da razão de normatizar e dar validade ao agir humano, pois, como falantes, os seres humanos participam de um entendimento racional e, no uso pragmático da linguagem,

\footnotetext{
${ }^{3}$ O curso de formação Chão da Escola, iniciado em 2016, é uma iniciativa da Secretaria de Educação do Piauí (SEDUC), cuja proposta é melhorar os indicadores educacionais do Estado, ao mesmo tempo em que qualifica os profissionais da rede estadual e permite uma aproximação da realidade da escola com a equipe da SEDUC, através de encontros semanais entre professores e técnicos das gerências regionais.
}

\begin{tabular}{|c|c|c|c|c|}
\hline Rovista Dialectus & Ano 9 & n. 20 & Outubro - Novembro 2020 & p. $10-26$ \\
\hline
\end{tabular}


estabelecem tais entendimentos e constituem estruturas do "mundo da vida", que não devem ser desvanecidas.

Isso será aprofundado por Habermas em sua célebre Teoria da Ação Comunicativa, na qual a ação de comunicar-se é entendida como "um processo cooperativo de interpretação, em que os participantes se referem simultaneamente a respeito de algo no mundo objetivo, no mundo social e no mundo subjetivo" (Habermas, 2012a, p. 171). Uma importante referência para os estudos sociais, especialmente por permitir um melhor entendimento dos processos de socialização e individuação na modernidade, tão caros ao universo contemporâneo e, também, por possibilitar discutir a ação pedagógica sob o tripé do entendimento habermasiano referenciado nos três mundos supracitados.

Todavia, não podemos esquecer que esse pensador alemão também ressalta o fato de que devido à crescente racionalização e burocratização da vida - já apontada por Weber e Marcuse - os indivíduos participantes desse mundo vital também estariam sujeitos a intervenções sistêmicas que, a partir das tentativas de neutralização dessa concepção de mundo pela ação instrumental, distorceriam a comunicação e produziriam as "patologias da modernidade". É isso que percebemos nas instituições de ensino, considerando que elas ainda são bastante permeadas pela razão instrumental; os fins acabam justificando os meios e, dessa maneira, valoriza-se mais os resultados estatísticos do que o processo em si mesmo. "A quantificação encerra um apelo irresistível, o número tem extraordinário valor simbólico, dando a impressão de objetividade.” (Rossi, 1980, p. 129).

A escola, enquanto instituição que pode substanciar a formação humana, passa a ser "colonizada pelo mundo sistêmico" de forma sorrateira, na medida em que se permite instrumentalizar os sujeitos sob o conceito de que o homem é um ser social que estabelece múltiplas relações para produzir e reproduzir sua vida em sociedade; uma espécie de “determinismo biológico”. Desde sua parceria com outras instituições, tais como a família, os movimentos sociais, as mídias, por exemplo, naturalizaram-se processos de formação calcados em um clássico cientificismo e tecnicismo prescricional.

Na visão de Habermas (2012b, p. 667):

A exigência de uma maior estruturação pedagógica do ensino e de uma democratização das estruturas de decisão não se combina sem mais nem menos com a neutralização do papel do cidadão, e menos ainda com o imperativo sistêmico que manda desconectar o sistema educacional do direito fundamental à educação e agregála ao sistema de empregos.

\begin{tabular}{|l|l|l|l|l|}
\hline Q & Dovista \\
\hline
\end{tabular}


A partir do exposto, cabe agora esclarecer a relação necessária entre os conceitos fundamentais da teoria comunicacional habermasiana - "mundo da vida e mundo sistêmico" com o contexto da educação formal, salientando a importância da consideração/valorização das duas categorias no processo de formação humana, tendo em vista que Habermas, mesmo não figurando entre os teóricos que frequentemente se ocupam com essa questão, empresta profícuas contribuições à área da educação. "É possível enxergar a perversa influência da racionalidade sistêmica sobre a educação, a começar por sua monetarização.” (Arantes, 1995, p. 73).

\section{Proposta habermasiana no eixo educativo}

\section{$1.1 \mathrm{O}$ mundo sistêmico e o mundo da vida em Habermas}

Só é possível identificar as possíveis contribuições de Habermas para o aperfeiçoamento da Teoria Crítica e para um projeto emancipador a partir da educação, se nos remetermos à teoria da modernização desenvolvida por esse autor, analisando a fertilidade dela no diagnóstico e análise conceitual da problemática que envolve a educação atual; no tocante ao nosso trabalho, iniciado pelo apelo normativo de um projeto político-pedagógico.

Habermas (2012a) desenvolve a teoria da modernidade pela ótica do confronto entre a razão que predomina no "mundo da vida" e a razão que orienta a "ação sistêmica". Sistema e mundo da vida são duas esferas que se opõem, mas, ao mesmo tempo, são interdependentes, constituindo um complexo que determina a forma de ser da sociedade moderna. "[...] proponho que a sociedade seja concebida, ao mesmo tempo, como mundo da vida e como sistema." (Habermas, 2012a, p. 220).

No longo caminho da configuração de sua Teoria do Agir Comunicativo, Habermas constitui, de um lado, uma diretriz segundo a qual é necessário levar a sério tanto as ciências que se desenvolvem em nível teórico e formal, como o "mundo da vida", concebido pelo senso comum. O conceito de alcançar o entendimento que decorre da "ação comunicativa" requer, por sua vez, a definição do contexto em que esses procedimentos acontecem. Isso porque aquilo que o falante quer dizer com seu pronunciamento, depende do conhecimento acumulado e realiza-se sob o pano de fundo de um consenso cultural anterior. É a partir desse ponto (concebido no senso comum) que esse autor introduzirá o conceito de "mundo da vida",

\begin{tabular}{|c|c|c|c|c|}
\hline Rovista Dialectus & Ano 9 & n. 20 & Outubro - Novembro 2020 & p. $10-26$ \\
\hline
\end{tabular}


entendido como o contexto não problematizável, o pano de fundo que propicia os processos de se alcançar o entendimento.

Essa construção teórica é produto de longos processos de argumentação, de reconstruções e apropriações críticas de princípios teóricos oriundos da filosofia e das ciências sociais, especialmente da teoria dos sistemas, de Luhmann.

Nas palavras de Habermas (2012b, p. 719):

Enquanto elo de ligação para uma teoria da racionalidade, a filosofia se encontra numa relação com as ciências que procedem de modo reconstrutivo - as que tomam como ponto de partida o saber pré-teórico de sujeitos que falam, julgam e agem de modo competente - e como os sistemas de saber coletivo legados por tradição, a fim de apreender as bases da racionalidade que se encontram na experiência e no juízo, no agir e no entendimento linguístico.

O "mundo da vida" é dividido em três componentes estruturais: cultura, sociedade e pessoa. A cultura pode ser entendida como o estoque de conhecimento do qual os atores suprem-se de interpretações quando buscam a compreensão sobre algo no mundo. A sociedade pode ser entendida como as ordens legítimas, através das quais os participantes regulam suas relações nos grupos sociais. Já a pessoa, pode ser entendida como as competências que tornam um sujeito capaz de falar e agir, ou seja, de compor sua própria personalidade (Habermas, 2012b, p. 220). Assim sendo, o "mundo da vida" é constituído por um saber implícito sobre o qual nós, normalmente, nada sabemos, porque ele é simplesmente não problemático, não atinge o limiar dos pronunciamentos comunicativos que podem ser válidos ou não.

Já o "mundo sistêmico" é a racionalização do mundo da vida pelo sistema econômico, político ou burocrático; sua problematização, sua "colonização" ou "mediatização", fruto de um aumento da complexidade num determinado sistema social, comumente preso em duas pontas: dinheiro e poder. Um mundo artificial, criado pelo homem visando ao êxito e ao domínio sobre a natureza. É o substrato do "mundo da vida", com ações dirigidas unicamente a fins estratégicos e hostis à emancipação humana, uma vez que substituem a linguagem e possibilitam a diferenciação dos "subsistemas de ação racional" que dizem respeito aos fins.

O "mundo do sistema" é a macroestrutura na qual se organizam as formas de produção do capitalismo mecânico e instrumental, que interfere no "mundo simbólico da vida". Mas é interessante observar novamente que essas duas dimensões do social se interpelam; a relação que os indivíduos estabelecem com ambas é dialética: ao mesmo tempo em que se relacionam no mundo prático da vida, relacionam-se com a ideologia do sistema. Não obstante

\begin{tabular}{|c|c|c|c|c|}
\hline QRomita Dialectus & Ano 9 & n. 20 & Outubro - Novembro 2020 & p. $10-26$ \\
\hline
\end{tabular}


a "colonização do mundo da vida" pelo aparato burocrático decorrente do processo de racionalização dos âmbitos de ação formalmente organizados, e cada vez mais complexos, que são a economia e administração estatal - tese bem construída por Habermas - a humanidade não está condenada ao “apocalipse”. Há possibilidades diante da progressiva racionalização do mundo vital sim, como ensaia Prestes (1995, p. 120):

A capacidade de aprendizagem dos membros da sociedade pode lhes permitir usar as ideias jurídicas e morais, a arte, a ciência e todo o saber decorrente das imagens do mundo para organizar novas formas de ação e promover uma nova forma de integração social.

Compreendendo a racionalidade como resultado de um processo de aprendizagem, Habermas mantem o instrumental teórico dos vários autores analisados por ele, que tem possibilidade de ser reformulado, através de um entendimento que deixe livre o potencial comunicativo da racionalidade. Interessa, aqui, referimo-nos, no âmbito deste estudo, ao caso específico do subsistema escolar como desdobramento da burocratização progressiva que assolou a razão moderna e submeteu as ações pedagógicas ao poder objetivo de um aparato autonomizado, conforme veremos a seguir.

\subsection{A escola como subsistema do mundo da vida}

Diante dos diferentes paradigmas que estão subjacentes aos currículos e práticas escolares $^{4}$, da burocracia, que "cuida" dos processos de ensino e normatiza procedimentos necessários à consecução do direito à educação formal, uma coisa podemos filtrar de forma responsável nesse contexto: a formação do sujeito está diretamente relacionada com os componentes estruturais do "mundo da vida", cuja realização depende diretamente do processo educativo, capaz de produzir competência interativa e de autonomia.

Porém, sendo a escola um subsistema desse mundo vital, ela se torna uma das tantas instituições ou organizações que servem para incorporar a racionalidade sistêmica atualmente dominante. A julgar por sua didática, que educa para a subserviência, reforça o controle e produz, em última instância, a violência - em seus multifacetados modos de ser. Isso porque tal prática obedece a um currículo exageradamente acentuado em elementos cognitivos e

\footnotetext{
${ }^{4}$ No livro Currículo: questões atuais, Elizabeth Fernandes de Macedo questiona o produto oferecido pela escola moderna, difundido em estudos que levaram a cabo a máxima de que um alargamento conceitual do termo currículo, a partir das inovações tecnológicas e científicas, seria fundamental para sua própria compreensão e inserção como política pública no mundo contemporâneo.
} 
instrumentais, o qual utiliza uma linguagem que funciona como mecanismo de dominação e de imposição de um discurso hegemônico, dificultando a tematização das categorias pedagógicas com as quais os professores lidam no dia a dia, deteriorando a inter-relação salutar entre teoria e prática.

Habermas (2012b) julga que o modelo prático de uma "comunidade de comunicação", não obstante seu caráter hipotético, pode explicar a reprodução simbólica dos grupos sociais, por meio de uma reconstituição, a partir de um ponto de vista interno, do "mundo da vida" desses grupos; porém, a dimensão sistêmica da reprodução da sociedade situase fora do alcance desse modelo. O compromisso com o caráter emancipatório da razão e a oposição ao não cognitivismo no campo da ética, implica a responsabilidade com a adoção de uma atitude que seja necessariamente participativa. Daí ser possível distinguir a linguagem como meio de intercompreensão e a linguagem apenas como meio para coordenar ações e socializar indivíduos. Habermas busca, a partir disso, superar o behaviorismo social de Mead, que não valoriza a comunicação voltada para o consenso e esbarra seus postulados numa perspectiva ontogenética, muito embora reconheça que o fenômeno da cooperação exija um controle social, regulando as atividades grupais - um interacionismo simbólico.

À medida que vai desvinculando a educação do "mundo da vida", a racionalidade sistêmica faz com que a educação desenvolva um papel ideológico que se torna comprometedor, do ponto de vista epistemológico, a partir do momento em que passa a tratar os conhecimentos de forma neutra, impedindo que se torne explícito o processo histórico-social de sua constituição e a vinculação desses com as instâncias normativas e políticas. Habermas atesta isso quando afirma que:

\footnotetext{
A eficácia peculiar desta ideologia reside em dissociar a auto compreensão da sociedade do sistema de referência da ação comunicativa e dos conceitos de interação simbolicamente mediada, e em substituí-lo por um modelo científico. Em igual medida, a auto compreensão culturalmente determinada de um mundo social de vida e substituída pela auto coisificação dos homens, sob as categorias da ação racional dirigida a fins e do comportamento adaptativo (Habermas, 1994, p. 74).
}

Ao tornar-se recurso de competitividade no processo produtivo capitalista, a valorização da educação passa a ser feita, prioritariamente, por critérios de lucratividade e eficiência, perdendo a sua conotação como valor epistemológico e como significação de valor social. Em outros termos, a educação passa a ser valorizada quase tão somente como recurso de ascensão econômica, ficando para um segundo plano sua validade enquanto recurso de qualificação subjetiva e de formação de uma visão social e política.

\begin{tabular}{|c|c|c|c|c|}
\hline Ronista Dialectus & Ano 9 & n. 20 & Outubro - Novembro 2020 & p. $10-26$ \\
\hline
\end{tabular}


A iniciativa sistêmica de introduzir uma orientação técnica e coercitiva na formação cultural e na educação, tem levado ao esfriamento da relação pedagógica e provocado o surgimento de novas patologias no campo da motivação. A inclusão abstrata dos indivíduos em processos pedagógicos formais, que não levam em conta os indivíduos concretos, suas vivências e necessidades, seu "mundo da vida", limita a interação dos indivíduos e dificulta a ação pedagógica do professor. Sob a orientação dos "princípios sistêmicos", a socialização escolar transforma-se em um mosaico de atos administrativos e burocráticos que, geralmente, acabam se tornando inconsequentes e ineficazes.

Prestes (1995) esclarece que a perda da pré-compreensão da prática comunicativa encolhe o mundo vivido e o torna apenas mais um subsistema. Quando a "integração sistêmica" interfere sobre a integração social, estabelece-se uma violência estrutural que ataca as formas de entendimento possível da "ação comunicativa", gerando perda de sentido, perda de legitimação, desestabilização das identidades coletivas, ruptura da tradição. Verifica-se, a partir disso, que as distorções das funções de reprodução cultural lançam elementos teóricos fecundos para compreender a ação educativa. Essas perturbações conduzem à manifestação de crises na formação dos sujeitos, que se afastam de referências tais como as identidades culturais, a tradição, os vínculos do mundo vivido, esvaziando o processo de formação educativa a uma mera competência técnica, operativa e cognitiva.

A análise de Habermas acerca das ciências sociais contribui para um enfrentamento crítico do contexto escolar. Ele considera como um dos problemas da modernidade a "colonização do mundo da vida pelo mundo do sistema" (Habermas, 2012b, p. 348). Nessa perspectiva, a estratégia da ação instrumental do "mundo do sistema" vai invadindo os espaços do mundo vital, desalojando e banindo a "ação comunicativa" da esfera social. Logo, um enfrentamento crítico é necessário para vislumbrarmos uma educação e uma sociedade na qual se cultiva uma comunicação que liberta da "coação sistêmica", capaz de estranhar o saber produzido historicamente, com vistas à sua revalidação coletiva e considerando a existência e a dignidade humanas como um valor maior que os valores proclamados pela dimensão econômica e administrativa.

1.3 A carência de uma racionalidade comunicativa nas ações pedagógicas

Como já explicado, a teoria habermasiana não versa literalmente sobre a escola, no seu sentido formal, mas isso não significa que estamos impossibilitados de aproximar seus

\begin{tabular}{|c|c|c|c|c|}
\hline QRomita Dialectus & Ano 9 & n. 20 & Outubro - Novembro 2020 & p. $10-26$ \\
\hline
\end{tabular}


pensamentos do "chão da escola", até porque este carece de um amplo arcabouço teórico que dê conta de suas problemáticas, que seja capaz de subsidiar uma proposta pedagógica que estimule a vivência democrática, a reflexão moral, buscando reestabelecer a relação intrínseca entre teoria e prática. Como aponta Prestes (1995), o que interessa especificamente nesta investigação é a pergunta pelas implicações de uma racionalidade comunicativa na práxis pedagógica, cuja base teórica originária não só lança raízes no pensamento clássico, com sustentação na filosofia do sujeito, como, sobretudo, cede à opção da modernidade por uma racionalidade instrumental.

Se desejamos formar pessoas aptas para atuar no mercado de trabalho, basta apenas uma educação voltada para a instrução e para a capacitação técnica, que reforce a competitividade e o individualismo. No entanto, se desejamos formar pessoas autônomas, politizadas e solidárias, necessitamos voltar nossos esforços para empreender uma educação formativa que aguce o "saber moral e político". Todavia, vale salientar que o processo educativo não deve se preocupar só com a formação de sujeitos moral e intelectualmente capazes de expressão verbal, mas também em construir uma competência comunicativa dialógica, levando em conta aquilo que temos de mais humano: a capacidade de pensar, falar e agir.

Para tanto, não há como fundamentar esse modelo de educação sem adentrar naquilo que Habermas coloca com excelência. Esse autor fundamenta sua filosofia prática numa ética filosófica cuja solidez se encontra estritamente numa argumentação racional. É a argumentação o ponto central da sua teoria moral. "Denominamos argumentação o tipo de discurso em que os participantes tematizam pretensões de validade controversas e procuram resolvê-las ou criticá-las com argumentos.” (Habermas, 2012a, p. 48). Essa crítica argumentativa só é possível num espaço democrático em que todos possam se posicionar livremente, numa práxis social de debate, discussão, persuasão e entendimento, que precede até mesmo as próprias instituições político-democráticas, mas que se realiza em seu amparo, e nelas se fortalece.

A ética comunicativa habermasiana busca estabelecer princípios morais na cotidiana atividade comunicativa do sujeito diante dos seus semelhantes, com o propósito de chegar a consensos através de atos de fala deles, visando à autorreflexão e à autoavaliação das práticas comuns a todos. Isso é cabível num espaço público de viés democrático como a escola - capaz de promover relações intersubjetivas in loco, em que questões morais voltadas para a dialogicidade se perfazem, isto é, a "razão prática", dialógica, intersubjetiva e comunicativa pode ser constituída, levando em conta que qualquer pessoa afetada pela discussão ética-moral

\begin{tabular}{|c|c|c|c|c|}
\hline Q Rovista Dialectus & Ano 9 & n. 20 & Outubro - Novembro 2020 & p. $10-26$ \\
\hline
\end{tabular}


é um interlocutor válido e deve ser tratado como tal. Acolher "o ponto de vista moral”, seria, então, defender interesses não individuais, mas sim, universalizáveis, que podem ser aceitos por todos (Cortina et al., 2005, p. 88-110).

Mesmo que, como já explicitamos, a lógica da escola impeça-a de viver realmente o saber político, moral e democrático em sua plenitude, pelas relações verticais que necessariamente há nesse contexto, tal verticalidade, no entanto, não impede que os relacionamentos que ali se dão sejam respeitosos, colaborativos, que se busque um entendimento recíproco na participação e organização do espaço escolar em sua totalidade. A escola carece, sem dúvidas, equilibrar as relações "assimétricas funcionais" com a "simetria democrática" que qualquer espaço dito público carrega consigo.

Analisando a ética do discurso habermasiano, e buscando na mesma, respostas, é possível perceber que através do diálogo, da defesa dos valores sociais como a liberdade, a justiça, a solidariedade, algo pode ser modificado na concepção moderna de sociedade. Nessa perspectiva, o diálogo é visto como um procedimento que respeita a individualidade, porém, busca um relacionamento intersubjetivo, pois, em um diálogo, "precisamos contar com pessoas, mas também com a relação que existe entre elas." (Morais, 1996, p. 99).

Podemos dialogar fortuitamente, sem expectativa alguma de verificar se desejamos, ou não, chegar a um entendimento sobre determinado assunto. Mas podemos também buscar um maior rigor nesse diálogo, porque o motivo que nos leva a dialogar, realmente nos preocupa, e faz com que desejemos verificar se há possibilidades de entendimento acerca desse motivo. Como a escola é constantemente permeada por "interesses sistêmicos", acaba por reforçar condutas, até desumanas, como a competitividade, a agressividade e os comportamentos discriminatórios, quase sempre camuflados em ações pedagógicas estéreis e carentes de reflexão.

Prefigurando essa vivência política, moral e democrática a partir desse subsistema de ação social, Habermas sustenta a ideia de que sua ética do discurso se apoia num agir comunicativo, o qual pressupõe interações comunicativas. "O mundo da vida comum em cada caso oferece uma provisão de obviedades culturais donde os participantes da comunicação tiram seus esforços de interpretação os modelos de exegese consentidos.” (Habermas, 1989, p. 166). As características próprias dessa "ação comunicativa" colocam exigências para uma participação estreitamente vinculada a alguns dos princípios de uma educação e de uma estrutura educacional voltadas para a construção de uma escola e de uma sociedade democráticas, politizadas. Além disso, o "chão da escola" pode ser um espaço no qual a

\begin{tabular}{|c|c|c|c|c|}
\hline QRomita Dialectus & Ano 9 & n. 20 & Outubro - Novembro 2020 & p. $10-26$ \\
\hline
\end{tabular}


reprodução dos componentes simbólicos do "mundo da vida", como cultura, personalidade e sociedade possam realmente acontecer, suplantando a velha compreensão repassada pela grade de conhecimentos e saberes que são objetos da reprodução cultural irrefletida.

Assim, pode-se afirmar que uma norma, determinação ou acordo só serão legítimos se forem obtidos em condições democráticas, e que uma determinada sociedade só poderá ser considerada democrática e cidadã quando as formas de integração social dominantes forem concretizadas por meio de normas, determinações e acordos, assim estabelecidos. Isso significa que a ação política visando à democratização da sociedade deve ser essencialmente democrática, na medida em que a forma de atuação política determina o conteúdo dos resultados a serem obtidos, o padrão ideal a ser buscado.

Se Habermas classifica o nível de progresso de uma sociedade através das etapas de reflexão que ela alcança, e se, na ação comunicativa, os sujeitos procedem de maneira estritamente racional e decidem apenas em função da maior solidez dos argumentos apresentados, então a sociedade que se organiza através da ação comunicativa apresentará um alto nível de racionalidade, a etapa de reflexão mais elaborada, e consequentemente representará também o estágio da evolução mais avançado. (Aragão, 1997, p. 55).

A partir daí, pode-se compreender com maior precisão a ideia de que o sentido do desenvolvimento prático-moral, que circunscreve as possibilidades concretas de encarnação institucional de novas formas de integração social, depende das práticas sociais efetivamente desenvolvidas no interior do quadro institucional da sociedade, inclusive da escola. Porém, as possibilidades de sucesso das discussões práticas são, evidentemente, restringidas pelos limites de uma realidade social de dominação, na qual os processos comunicativos são sistematicamente bloqueados, lacrados. À falta de uma "cultura política", soma-se à imobilização diante das diretrizes de um Estado clientelista e gerencialista. Isso vem a ser um obstáculo à "descolonização do mundo vivido", certamente, mas é motivo de resistência e enobrecimento do potencial racional com o qual o homem moderno se mune, e que segundo Habermas (2012b), possibilita a questão da igualdade, não de modo jurídico formal, mas de modo concreto de participação nos processos decisórios, premissa essa já contemplada pela Carta Magna do nosso país (BRASIL, 2006) e pela Lei de Diretrizes e Bases da Educação LDB (BRASIL, 1996).

De acordo com Habermas (2012a, p. 41), "todo dissenso representa um desafio peculiar para esse pano de fundo do mundo da vida." Não obstante haja dissensos entre as diversas opiniões que se entrecruzam no ambiente escolar, isso não cria um problema

\begin{tabular}{|c|c|c|c|c|}
\hline Q Rovista Dialectus & Ano 9 & n. 20 & Outubro - Novembro 2020 & p. $10-26$ \\
\hline
\end{tabular}


insuperável, pois nas estruturas da comunicação, esse pressupõe-se o que não prejudicaria a possibilidade do entendimento. Conflitos podem ser salutares. Considerando isso, Habermas nos oferece inúmeras possibilidades de repensarmos a educação na contemporaneidade, apontando caminhos concretos para uma práxis pedagógica genuinamente emancipatória, na qual seremos capazes de colaborar efetivamente com uma proposta na qual todos se sintam parte do processo educacional, e necessários, enquanto seres sociais que colocam suas ideias para normatização do coletivo e discutem-nas racionalmente, buscando sempre o melhor argumento para pensar a convivência do grupo, sua práxis, sua construção histórica e, também, as contradições inerentes a ela, isto é, para repensar suas ações e reestruturar o "chão da escola" para a formação de sujeitos comunicativamente competentes, esclarecidos diante dos ditames da lógica da razão instrumental.

\section{Considerações finais}

Unir a proposta sociológica e filosófica de J. Habermas às discussões sobre escola, ações pedagógicas, currículo e tudo o que se insere no âmago da educação formal tem apontado para muitos caminhos possíveis, e que parecem promissores. Atualmente, já não são poucos os textos que buscam alinhar o pensamento habermasiano à área educacional, enxergando a "comunicação intersubjetiva" como categoria indispensável para levar a uma suposta emancipação. Com os pés fincados, a priori, em sua tão conhecida obra Conhecimento $e$ Interesse e, a posteriori, em sua ilustre Teoria do Agir Comunicativo, diversos textos vêm se dedicando intensamente na busca por clarificar o potencial pedagógico da teoria crítica desse cientista alemão.

Neste artigo, mais um estudo nessa perspectiva, procuramos discutir, sem intenção de exaurir o tema, a possibilidade de um reencontro entre teoria e práxis no "chão da escola", tendo como suporte, não só epistemológico, mas antropológico, a teoria comunicacional habermasiana, pois ao trabalhar o conceito de "ação comunicativa", Habermas (2012b) introduz um novo componente na busca do conhecimento verdadeiro, capaz de conduzir, via teoria da linguagem, à busca da emancipação. Assim, analisar alguns conceitos-chave de sua teoria, tão engajada com o fenômeno da formação humana, permite-nos, de forma mais esclarecida, manter uma postura reflexiva e crítica frente ao modelo de educação instituído nas escolas públicas atuais, ainda muito presas ao ideário iluminista de racionalidade emancipatória.

\begin{tabular}{|c|c|c|c|c|}
\hline Rovista Dialectus & Ano 9 & n. 20 & Outubro - Novembro 2020 & p. $10-26$ \\
\hline
\end{tabular}


Tomar como referencial teórico-metodológico a teoria crítica habermasiana implica uma compreensão histórico-dialética da educação e da formação humana. Tendo entendimento de que, para essa teoria, o papel exercido pelo trabalho educativo é de suma importância, já que, sem ele, ou com o empobrecimento dele, o indivíduo não se desenvolveria em suas potencialidades, e dificilmente experimentaria o esclarecimento e a emancipação. Trata-se de um posicionamento político, no qual a postura é em defesa da transmissão e discussão aberta dos conhecimentos filosóficos, sociológicos, culturais e científicos, acreditando que todos os indivíduos, independentemente de sua diferenciação social, tenham acesso ao espaço público dos saberes acumulados historicamente pelo conjunto dos homens e ao diálogo franco nesse espaço, camuflado por lampejos de democracia.

$\mathrm{O}$ recorte que fazemos aqui, permite-nos perceber que Habermas é um pensador que mantém a esperança no poder emancipador e na função esclarecedora da racionalidade humana. Ainda que admita que há algum tempo a racionalidade instrumental e a educação se tornaram mecanismos de opressão e de obliteração da dignidade dos seres humanos, ele entende que nem toda educação é opressora, e que nem todo saber é necessariamente destrutivo. $\mathrm{Ou}$ seja, razão não é exclusivamente instrumento de dominação e exploração; mesmo em um mundo em que cresce a "racionalidade sistêmica", a razão continua mantendo um potencial emancipatório. Em Habermas, a emancipação é entendida como um processo que ocorre “à medida que os homens pensam, falam e agem coletivamente de forma racional, libertando-se não só da forma de conceber o mundo a si impostas pela tradição, como das formas de poder hipostasiadas pelas instituições.” (Aragão, 1997, p. 55).

Diante disso, qual a possibilidade de acontecer uma proposta de educação emancipadora, nesse contexto que progressivamente domina a racionalidade instrumental? A teoria da racionalidade comunicativa apresenta alguma perspectiva de resistência ou de mudança diante desse contexto de "colonização sistêmica", no qual a relação entre teoria e práxis encontra-se tão desgastada? Bem, acreditamos que esse potencial existe e, se pensamos em empreender uma proposta educativa que realmente valorize a formação democrática e ética, precisamos acreditar nos princípios da racionalidade comunicativa como essenciais para pautarmos nossa caminhada em busca do resgate de um mundo vital menos corrompido, embora saibamos que as ações instrumentais cruzam-se o tempo todo com as razões comunicacionais, e o que de fato podemos perseguir é, sem simplificar demais as coisas, instituir na escola um processo capaz de mediar "racionalidade sistêmica" e "racionalidade comunicativa", cujo

\begin{tabular}{|c|c|c|c|c|}
\hline Rovista Dialectus & Ano 9 & n. 20 & Outubro - Novembro 2020 & p. $10-26$ \\
\hline
\end{tabular}


resultado será sempre uma síntese precária, suscetível à revisão permanente e à nova reconstrução.

Pensar modos de lidar com subjetividades diversas num mesmo espaço didático (cuja função social é bem definida) é intrigante. Há textos e contextos envolvidos e os processos interativos nesse momento são essenciais para a permissão do desenvolvimento do caráter analítico-reflexivo de todos os politicamente e moralmente envolvidos com a ideia de formação humana. Se tivermos em mente que a escola é um espaço profissional de formação, uma comunidade educativa, tendo, portanto, influência cirúrgica nas tantas personalidades que ali se relacionam, então, há de se convir que tais personalidades não se constroem sozinhas ou isoladas, há dinâmicas de saberes envolvidas e que carecem ser coletivamente aprofundadas, pois pessoas e processos se confundem (Rodrigo, 2009).

O conhecimento não é desprovido de valores, e muito menos está localizado acima da realidade social e dos relacionamentos interpessoais. Segundo Arantes (1995, p. 51): “[...] unidade de ensino não pode ser confundida com linearidade de ideias, isso seria uma falácia tamanha." Se assim for, estaremos alimentando uma ideologia na qual a cidadania é transmitida de acordo com a racionalidade dominante, e que prevê uma harmonia social que nega os conflitos sociais próprios de uma sociedade com tantas referências distintas. Constata-se, assim, que o reconhecimento desse pseudoprogresso da razão moderna é condição necessária, embora não suficiente, à emancipação

O que Habermas exige de nós é uma postura crítica permanente diante desta "racionalidade sistêmica" que há algum tempo vem adentrando os portões das escolas, atingindo a educação e, consequentemente, a sociedade em seu todo. Diante dessa tensão, e com o intuito de retomar o projeto da modernidade, agarra-se na racionalidade comunicativa como saída para o impasse deixado por seus predecessores, fundamentando na interação, via linguagem do "mundo da vida", a constituição da realidade social, para assim resgatar um núcleo sadio e racional da humanidade, que garante a resistência contra a colonização e a manutenção da possibilidade de emancipação, vinculada à restauração da comunicação livre de dominação, presente nas estruturas vitais da sociedade.

Esse "mundo da vida" constitui-se, portanto, em um conceito central na reconstrução que o autor propõe para as ciências sociais e para a educação. A redescoberta da natureza da racionalidade comunicativa não coagida, que se mantém agindo no mundo vital, faz Habermas acreditar na possibilidade do progresso humano no sentido de sua libertação. Na racionalidade comunicativa que instaura essa dimensão social, ele identifica um elemento de

\begin{tabular}{|c|c|c|c|c|}
\hline Q Rovista Dialectus & Ano 9 & n. 20 & Outubro - Novembro 2020 & p. $10-26$ \\
\hline
\end{tabular}


resistência contra a dominação total da "racionalidade sistêmica", instrumental. Essa resistência não é irracional, mimética, mas racional, utópica; ela não aponta para um retorno ao estado natural, mas para a possibilidade da realização de uma situação menos opressora na história, entendendo que esses dois mundos retroagem e retroalimentam-se constantemente, estando a produção simbólica do "mundo da vida" atrelada à produção material do mundo sistêmico. "Entretanto, se, em vez de absolutizar a perspectiva do sistema ou a do mundo da vida, tentássemos correlacioná-las, o desengate entre sistema e mundo da vida não apareceria como um processo de diferenciação de segunda ordem.” (Habermas, 2012b, p. 280).

A teoria alternativa comunicacional de Habermas pode servir como uma referência para que os educadores repensem e mudem sua visão sobre o poder e o papel da educação no atual contexto social, resgatando as estruturas primárias de formação dos sujeitos. O autor reacende a crença no poder da racionalidade humana, levando-nos a acreditar que a razão é capaz de reconstruir e superar as limitações de certas concepções produzidas por ela mesma. Para tanto, é preciso recuperar a experiência esquecida da reflexão, tornando a escola e, de modo especial, fóruns discursivos como o "chão da escola" um espaço público de exercício do pensar, como condição necessária para a formação da opinião pública. A teoria da intersubjetividade aponta, ademais, para a necessidade de uma abordagem crítica e reconstrutiva da relação entre teoria e prática, tendo por referência a mediação que se configura entre essas duas dimensões sob a mediação da "ação comunicativa", o que pode ser um ponto de partida muito produtivo no desenvolvimento do conhecimento e, por sua vez, na contribuição de ações orientadas para a conscientização da comunidade escolar a respeito da função integradora e emancipadora da escola.

\section{Referências}

ARAGÃO, L. M. de C. Razão comunicativa e teoria social crítica em Jürgen Habermas. 2. ed. Rio de Janeiro: Tempo Brasileiro, 1997.

ARANTES, P.; SILVA, F. L. Filosofia e seu ensino. 2. ed. Petrópolis, RJ: Vozes; São Paulo: EDUC, 1995.

BRASIL. Ministério de Educação e Cultura. LDB - Lei nº 9.394/96, de 20 de dezembro de 1996. Estabelece as diretrizes e bases da Educação Nacional. Brasília: MEC, 1996.

BRASIL. Constituição da República Federativa do Brasil de 1988. Texto constitucional promulgado em 5 de outubro de 1988, com as alterações determinadas pelas Emendas Constitucionais de Revisão nos 1 a 6/94, pelas Emendas Constitucionais nos 1/92 a 91/2016 e pelo

\begin{tabular}{|c|c|c|c|c|}
\hline QRomita Dialectus & Ano 9 & n. 20 & Outubro - Novembro 2020 & p. $10-26$ \\
\hline
\end{tabular}


Decreto Legislativo no 186/2008. Brasília: Senado Federal, Coordenação de Edições Técnicas, 2006.

CORTINA, A.; MARTÍNEZ, E et al.. Ética. São Paulo: Loyola, 2005.

HABERMAS, J. Conhecimento e Interesse. In: Os Pensadores. 2. ed. São Paulo: Abril Cultural, 1983.

Consciência moral e agir comunicativo. Tradução Guido A. de Almeida. Rio de Janeiro: Tempo Brasileiro, 1989.

Técnica e ciência como ideologia. Lisboa: Edições 70, 1994.

Teoria do Agir Comunicativo: racionalidade da ação e racionalização social. Tradução de Paulo Astor Soethe; revisão e tradução de Flávio Beno Siebeneichler. São Paulo: Editora WMFMartins Fontes, 2012a. vol. 1.

Teoria do Agir Comunicativo: sobre a crítica da razão funcionalista. Tradução de Flávio Beno Siebeneichler. São Paulo: Editora WMFMartins Fontes, 2012b. vol. 2.

MACEDO E. F. Novas Tecnologias e currículo. In: Currículo: Questões atuais. São Paulo: Papirus, 1997.

MORAIS, Regis de. Sala de aula: que espaço é esse? 10. ed. Campinas, SP: Papirus, 1996.

PRESTES, N. M. H. Educação e racionalidade: conexões e possibilidades de uma razão comunicativa na escola. 1995. Tese de Doutorado. Universidade Federal do Rio Grande do Sul, 1995.

RODRIGO, L. M. Filosofia em sala de aula: teoria e prática para o ensino médio. Campinas: Autores Associados, 2009.

ROSSI, W. G. Capitalismo e educação: contribuição ao estudo crítico da economia da educação capitalista. 2. ed. São Paulo: Moraes, 1980.

SAVIANI, D. Escola e Democracia. São Paulo: Autores Associados, 2009.

VEIGA, I. P. A. (Org.). Projeto político-pedagógico da escola: uma construção possível. São Paulo: Papirus, 2011.

\begin{tabular}{|l|l|l|l|l|}
\hline Q & Ano 9 ialactus & Ano 20 & Outubro - Novembro 2020 & p. $10-26$ \\
\hline
\end{tabular}

